\title{
Keratin 86 is up-regulated in the uterus during implantation, induced by oestradiol
}

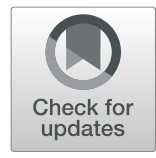

He Zhang ${ }^{1 *}$, Huashan Zhao ${ }^{2}$, Xi Wang $^{1}$, Xiaolin Cui ${ }^{1}$ and Lingling Jin ${ }^{1}$

\begin{abstract}
Background: Uterine receptivity is one of the determinants of embryo implantation, which is responsible for pregnancy success. Aberrant embryo implantation due to disrupted uterine receptivity is usually found in ovarian hyperstimulation induced hyperoestrogen patients.

Results: This study identified keratin 86 (KRT86), a fibrous structural protein, which was upregulated in uterine endometrium during peri-implantation. Using a hyperoestrogen mouse model established in a previous study, we found abnormal oestradiol (E2) levels during pre-implantation could trigger high expression of Krt86 in the uterine epithelium. In an ovariectomised mouse model, combining oestrogen receptors ERa and ER $\beta$ knockout mice models, uterine Krt86 was found to be up-regulated after E2 treatment, mediated by nuclear ERa. Furthermore, we found progesterone (P4) could ameliorate Krt86 expression, induced by abnormal E2.
\end{abstract}

Conclusions: These results revealed the dynamic expression and regulation of Krt86, especially in hyperoestrogen treated mice, indicating it might act as a marker for non-receptive uterus.

Keywords: Implantation, Uterus, Oestrogen, Progesterone, Keratin 86

\section{Background}

Embryo implantation establishes pregnancy [1]. During this process, uterine endometrium acquires the ability to accept embryo implantation, which is called uterine receptivity, and is regulated by steroid hormones. Precisely regulated progesterone (P4) and oestrogen (E2) determine uterine receptivity and embryo implantation. In mice, increased ovarian $\mathrm{P} 4$ insures uterine receptivity, and then a small surge of oestrogen triggers the initiation of embryo implantation. Disturbances of $\mathrm{P} 4$ and E2 during this process can affect implantation, for example, hyperoestrogen induced by ovarian hyperstimulation in in vitro fertilisation (IVF) treatment disrupts embryo implantation. Although different genes have been found to participate in uterine receptivity and embryo implantation regulation, gene changes under the stress of implantation remain less well-known. Given that implantation could be considered a form of xenoimplantation, proteins which regulate epithelial cell sensing and that protect against outside stress may participate in

\footnotetext{
* Correspondence: zhanghe0621@163.com

${ }^{1}$ College of Basic Medical Sciences, Dalian Medical University, No. 9 West

Section Lvshun South Road, Dalian 116044, Liaoning, China

Full list of author information is available at the end of the article
}

this process. Keratin proteins are a structural component of cells that protect against mechanical stress. Many kinds of keratins exist in adult epithelial cells, for instance, keratin intermediate filaments protect epithelial cells from various stresses that cause cell rupture and death [2]. The study of many human diseases and murine knockout models has testified to its importance as a mechanical stabiliser in epithelia, when integrity is destroyed [3]. Keratin 86 (KRT86), a type II hair keratin, belongs to the keratin gene family, which can form hair and nail structures by heterodimerising with type I keratins [4]. Mutations in Krt86 are related to a rare hereditary hair loss disorder, monilethrix [5, 6], where hair has a beaded structure, with elliptical nodes and constricted internodes, and is sensitive to damage from weather conditions and fracture [5]. Given the role of KRT86 in ameliorating outside stress, its presence in uterine epithelium might maintain the cytoskeleton, to facilitate embryo implantation.

In the current study, using hyperoestrogen and ovariectomised mouse models, we found that Krt86 was specifically expressed during embryo implantation, and was up-regulated by E2 through the nuclear oestrogen receptor ER $\alpha$ pathway. In the hyperoestrogen mouse model, 
which we established in previous study, Krt86 was found to be up-regulated in the mouse uterus, indicating it might participate in the regulation of uterine receptivity, especially in ovarian hyperstimulation syndrome patients.

\section{Results}

We first examined Krt86 expression during early pregnancy, for days 1-5 (Fig. 1a). Although low krt86 was found from day 1 to day 3 , on day 4 and day 5 it was significantly up-regulated (Fig. 1b). KRT86 protein changes in the uteri showed a similar pattern as the gene expression results (Fig. 1c, d).

Immunohistochemistry analysis for KRT86 protein on the morning of day 4 showed weak expression in the epithelium, compared with the oil treated control group (Fig. 2a, b, g, h). However, enhanced staining of KRT86 was observed after E2 treatment. Notably, KRT86 was specifically localised to the epithelium of uteri (Fig. 2c, d), compared with the oestrogen receptor antagonist ICI 182780 treated group (Fig. 2e, f), suggesting that KRT86 might play a role in hyperoestrogen-induced uteri.

To verify whether Krt86 expression was induced by supraphysiological levels of E2 during peri-imlplantation, we treated pregnant mice with E2 (>50 ng) on the morning of day 4 (8:30) [7], and collect samples at different time (Fig. 3a). Using this hyperoestrogen-induced pathophysiological mouse model, we examined Krt86 expression levels in day 4 uteri (untreated, treated with E2 and treated with ER antagonist ICI 182780), by RT-PCR and western blotting. Expression of Krt86 was observed on the morning and afternoon of day 4, with high expression after E2 treatment. For the ER antagonist treated group, Krt86 was hardly detected; however, when also treatment with E2 Krt86 had a similar expression to that in mice with E2 alone, on the morning of day 4 (Fig. 3b). Similar results were obtained through real-time PCR (Fig. 3c). Gene expression levels were also reflected by protein analysis, with Krt86 showing high expression in response to E2 treatment (Fig. 3d, e).

As ERs were present as two types, ER $\alpha$ and $E R \beta$, we used ER $\alpha$ and ER $\beta$ knockout mice combined with an ovariectomised mouse model to identify which one contributed to the high expression of Krt86. In wild type (WT) mice, Krt86 showed transient expression at $4 \mathrm{~h}$ and $8 \mathrm{~h}$ after E2 treatment, due to an E2-indued affect (Fig. 4a). However, in ER $\alpha \mathrm{KO}$ mice, there was no expression of Krt86, suggesting that ER $\alpha$ regulated Krt86

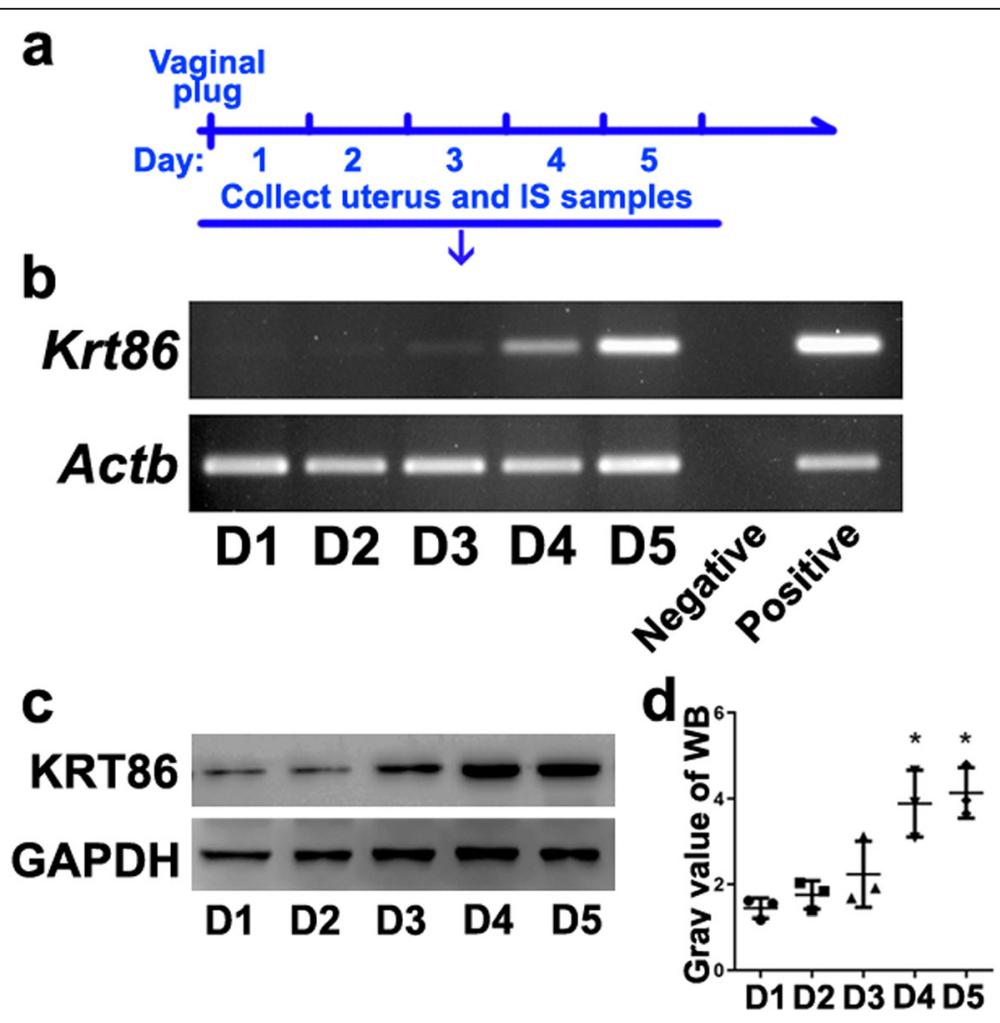

Fig. 1 Specific expression of Krt86 during implantation. a Schematic diagram of sample selection in days. IS indicates implantation site. b RT-PCR test of Krt86 expression during embryo implantation for days 1-5. c KRT86 protein levels assessed by western blot, during implantation days 1-5. d Grayscale values of KRT86 protein test. The data is presented as means \pm standard deviation (SD), and asterisks indicate statistically significant differences with a $P$ value $<0.05$ 


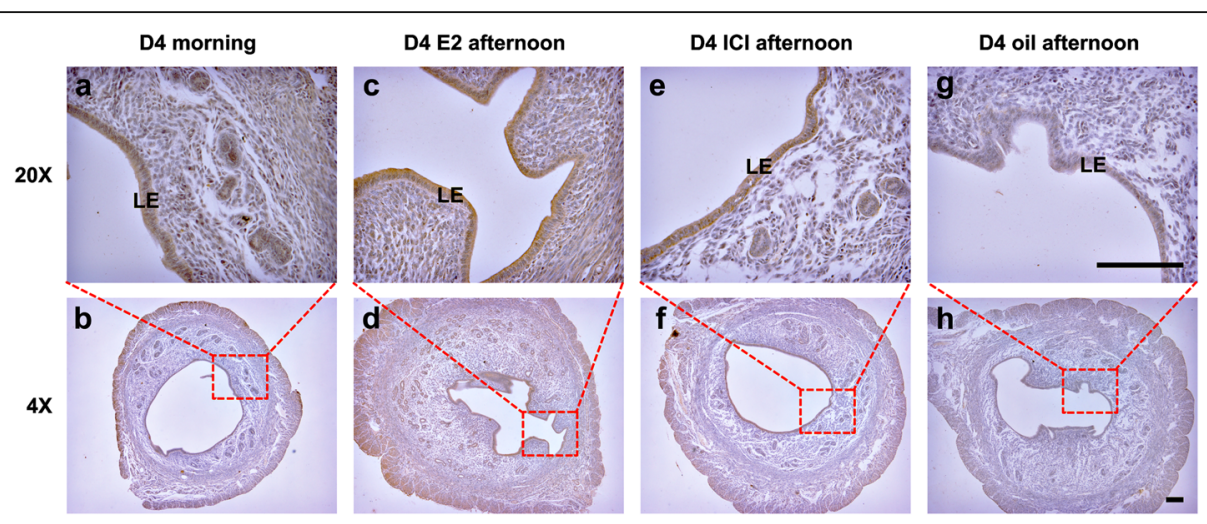

Fig. 2 KRT86 is located in the epithelium of the uterus and shows strong expression after treatment with E2. a, b KRT86 localisation in uterus on morning of day 4 sample. c, $\mathbf{d}$ KRT86 expression on afternoon of day 4, after treatment with E2. e, $\mathbf{f}$ KRT86 expression on day 4 after treatment with oestrogen receptor antagonist ICI 182780. $\mathbf{g}$, h KRT86 expression for control group after treatment with oil. LE, luminal epithelium. Bar $=$ $500 \mu \mathrm{m}$. The staining of KRT86 antibody is brown, the nucleus is blue

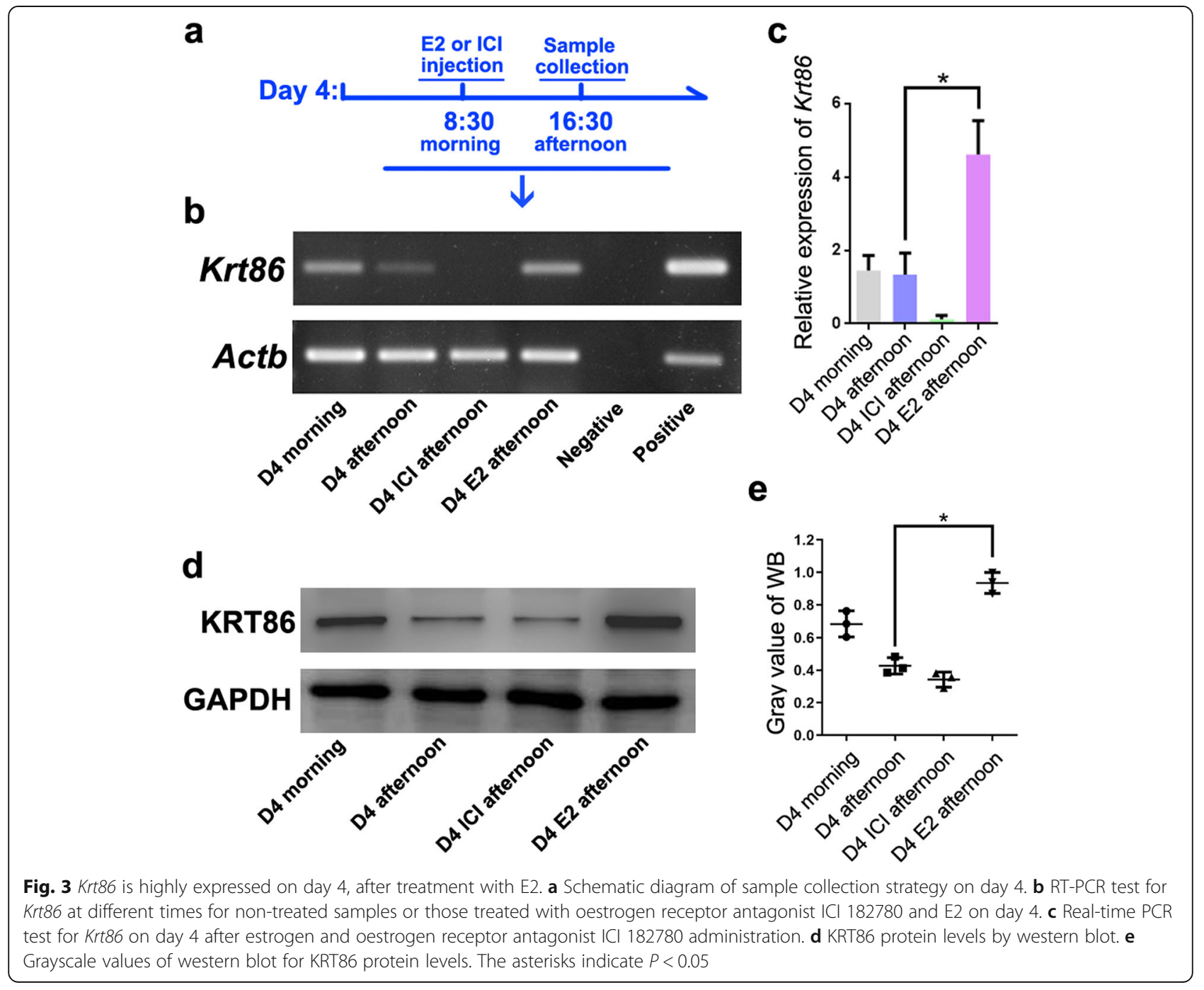




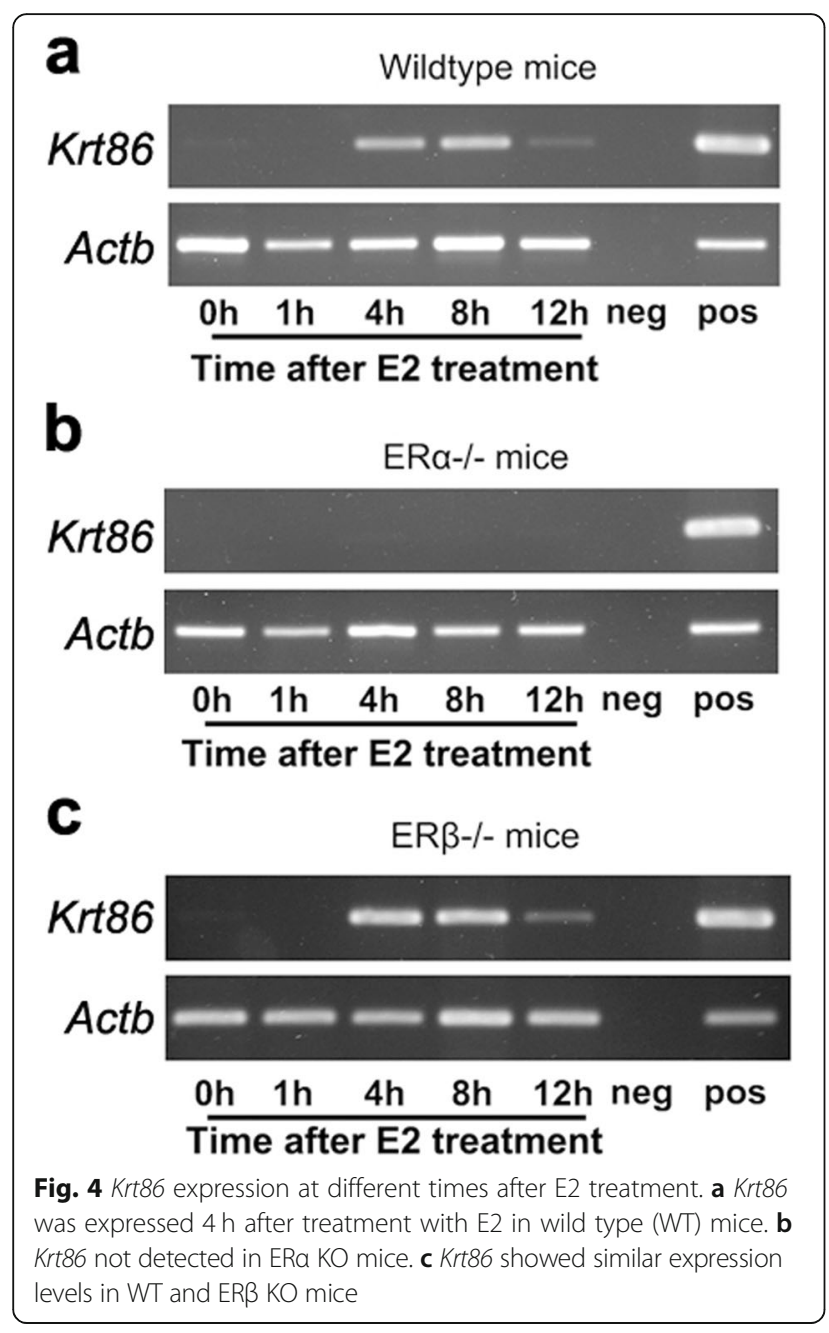

expression (Fig. 4b). By contrast, treating ER $\beta$ KO mice with E2 resulted in a similar pattern of Krt86 expression as the WT group (Fig. 4c).

In addition, treatment with only P4 of ovariectomised mice hardly changed Krt86 expression levels (Fig. 5a). However, expression of $K r t 86$ weakened at $8 \mathrm{~h}$ after coinjection of P4 with E2 (Fig. 5b), suggesting that a hyperoestrogen state up-regulated Krt86 expression, and P4 treatment antagonised this up-regulation to some extent.

\section{Discussion}

This study demonstrated that uterine KRT86 was dynamically expressed during early pregnancy, and was regulated by oestrogen through ER $\alpha$ signalling. It was also up-regulated in the hyperoestrogen uterus and could be down regulated by $\mathrm{P} 4$. This dynamic regulation of KRT86 by E2 suggested that structural changes in the uterus epithelium might be one of reasons for embryo implantation failure in clinical IVF.

Prior to implantation, the endometrial epithelium becomes flattened in order to establish a connection between the embryo and the uterus. Along with embryo migration and invasion in uteri, these mechanical stresses would trigger changes in the structure of the epithelium cytoskeleton. It has been reported that enhanced uterine oestrogen leads to defective luminal epithelium characterised by more epithelial proliferation and abnormal surface transformation [8], suggesting a defective cytoskeleton arrangement in the epithelium. For instance, E-cadherin, a transmembrane adhesion molecule, regulates the cytoskeleton dynamically [9], which is up-regulated in the luminal epithelium before implantation [10], indicating that remodelling of the cytoskeleton in epithelial cells is critical for embryo implantation. E-cadherin is a prerequisite for blastocyst implantation [11]; however, persistent expression of Ecadherin results in implantation failure [12, 13], due to disorganisation of cellular structures. Given that Krt86 showed dynamically expression in the current study, we presumed Krt86 might participate in the process of uterine surface transformation. Therefore, further study of Krt86 in subcellular structures during implantation might reveal more information about the function of KRT86 in the uterus.

The keratin skeleton allow rapid local reconstruction. Keratin filaments are considered to be an important part of the cytoskeleton in epidermal cells. Keratin filaments have high viscoelasticity and flexibility, but it would be hardened with the increase of deformation. It could bend quickly without breaking and recover quickly after withdrawing the deformation pressure $[14,15]$. Keratin can reestablish itself depending on the condition change such as salt or $\mathrm{PH}$, which may contribute to the hardness change of keratin. Therefore, we speculated that during embryo implantation KRT86 protein expression increased in the epithelial cells of the uterine cavity, which enhanced the hardness of uterine cavity epithelium, facilitating the embryo implantation. However, under the high estrogen level, the epithelial epithelium KRT86 was overexpressed, which broke the balance that affected embryo attachment and penetration.

There are few reports on the expression and function of KRT86 in the uterus; however, some information can be obtained from homologues. For example, KRT85, another member of the keratin family, is also expressed in the uterus [16]. Like KRT86, it also forms type II hair keratin and nails, and is a basic protein [17]. In a vascular endothelial growth factor (VEGF) regulating implantation model, VEGF repression caused implantation failure, and $K r t 85$ is dramatically up-regulated (1000 fold), indicating a role of keratin during implantation [16]. In alopecia areata (AA) lesional skin, $K r t 85$ and $K r t 86$ were significantly repressed [18]. They are early and middle markers for Alopecia areata, respectively [19, 20]. Krt86 and Krt85 have 91\% sequence similarity. In Hirosaki hairless rat, Krt86 and Krt85 could not be detected [21], suggesting these 


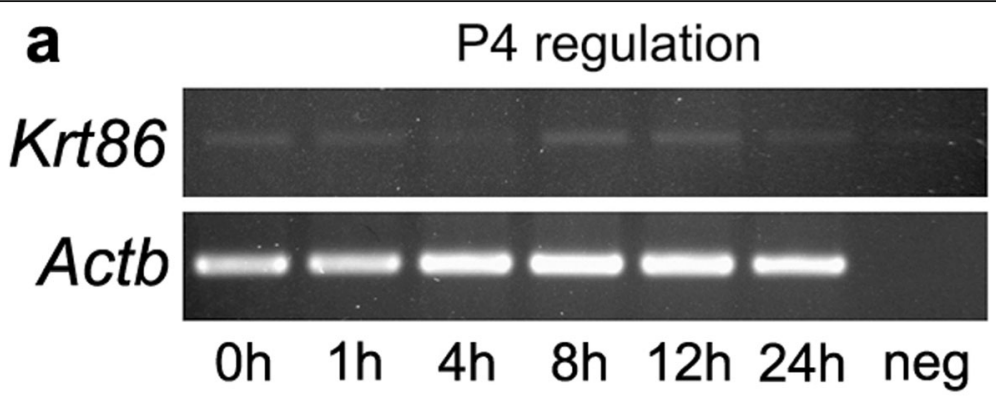

b

$\mathrm{E} 2+\mathrm{P} 4$ regulation

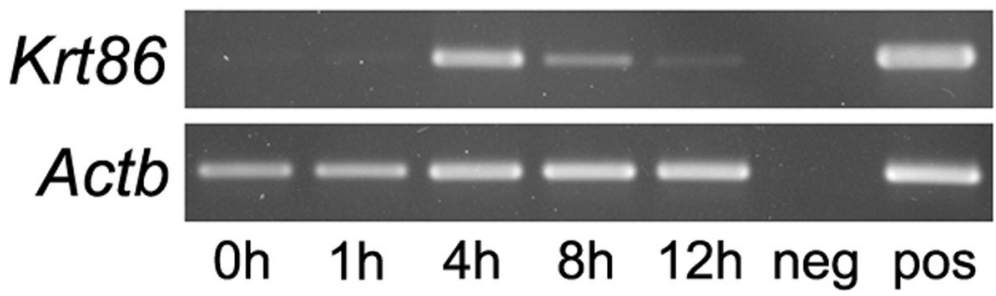

Fig. 5 Krt86 expression test at different times after P4 treatment. a RT-PCR test for Krt86 expression after P4 treatment. b RT-PCR test for Krt86 expression after P4 and E2 treatment

genes are related with hair follicle development. Based on these reports, we proposed KRT86 was responsible for formation of epithelium of the endometrium, functioning with other keratins during implantation. However, as shown in this current study, high level E2 increased keratin expression, leading to excess keratinisation that might affect implantation.

$E 2$ acts by binding to ER $\alpha$ and ER $\beta$, which are a kind of nuclear steroid hormone receptor [22, 23]. Oestrogen signalling is selectively activated or inhibited based on ER $\alpha$ and ER $\beta$ [24]. Using ER $\alpha$ and ER $\beta$ knockout mice, the general role of oestrogen signalling has been demonstrated [25, 26]. Male and female ER $\alpha$ knockout mice are infertile, whereas ER $\beta$ female mice show inefficient fertility, while ER $\beta$ male mice have no apparent defect [24, 27]. Some relevant literature showed that the ER $\alpha$ highly regulates Krt86 expression after E2 treatment [28, 29]. However, in other cell line models, the ER $\beta$ would not affect the Krt86 expression [30-33]. In addion, E2 is critical for the reproductive organ to achieve pregnancy [34]. Implantation is a complicated process triggered by an E2 surge [35]. Correspondingly, in this current study, ER $\alpha$ was identified as being essential for regulation of Krt86, suggesting that it affected the epithelium by modulating keratins. Our data suggested that the KRT86 might be a valuable marker for monitoring IVF and embryo transfer outcomes.

\section{Conclusions}

In summary, the present study showed Krt86 was highly expressed in the presence of physiological and supraphsiological levels of E2. An aberrant cytoskeleton of the uterus epithelium could be an aspect of implantation failure. Therefore, specific expression of Krt86 induced by E2 warrants further investigation.

\section{Methods \\ Mice}

Female adult ICR mice (7-8 weeks old) were purchased from the Laboratory Animal Centre of Dalian Medical University, China. ER $\alpha$ and ER $\beta$ knockout mice were fed in the Laboratory Animal Centre of Dalian Medical University. The Guidelines for the Care and Use of Animals in Research were followed. Care of mice and their handling were conducted in accordance with the Animal Research Committee guidelines of Dalian Medical University. Mice were allowed free access to water and food in $12 \mathrm{~h}$ light, $12 \mathrm{~h}$ dark conditions. Adult virgin female mice were mated with fertile males at room temperature $\left(25^{\circ} \mathrm{C}\right)$. The morning of finding a vaginal plug was designated as day 1 of pregnancy. Mice were killed at 8:30 a.m. on various days of pregnancy to collect uterine samples, especially for the implantation site (IS). Pregnancy on days 1-4 was confirmed by recovering embryos from the reproductive tracts, and IS on day 5 of pregnancy were identified by intravenous injection of 0.4 $\mathrm{ml} 0.5 \%$ trypan blue in saline $5 \mathrm{~min}$ before the mice were killed. Mice were euthanized by dislocating their neck.

\section{Drug treatment}

To induce the supraphysiological E2 mice model, dosage of E2 was as previously described [7]. Corn oil containing 
100 ng E2 was administered by subcutaneous injection (s.c.) at 08:30 a.m. on the morning of day 4, with vehicle group mice being injected with oil alone. Some of the day 4 mice were injected with the oestrogen receptor antagonist ICI 182780 (100 $\mu \mathrm{g} / \mathrm{mouse})$ at 08:30 a.m., with uteri being collected on the afternoon of day 4.

To determine the effects of E2 on Krt86 expression in uteri, mature female ER $\alpha$ and ER $\beta$ knockout ICR mice were ovariectomised. After two weeks rest, they were then treat with subcutaneous injections of E2 (Sigma; $100 \mathrm{ng} /$ mouse) dissolved in corn oil (Santa). Uteri from these mice were collected at $0,1,4,8$, and $12 \mathrm{~h}$ after each treatment, and frozen in liquid nitrogen for further analysis (three mice per time point).

To examine the effects of $\mathrm{P} 4$ on the expression of Krt86 in uteri, ovariectomised mice had s.c. injections of P4 (2 mg/mouse). To neutralise the effect of E2, a coinjection of P4 (2 mg/mouse) was administered along with E2 (100 ng/mouse). Mice were killed, and their uteri were collected at $0,1,4,8,12$ and $24 \mathrm{~h}$ after each treatment, and frozen in liquid nitrogen for further analysis (three mice per time point).

\section{Reverse transcription polymerase chain reaction (RT-PCR) and real-time PCR}

Total RNA was isolated from uteri using TRIzol reagent (Invitrogen), according to the manufacturer's instructions. Total RNA $(2 \mu \mathrm{g})$ was reverse-transcribed into cDNA using Moloney murine leukemia virus (M-MuLV) reverse transcriptase (M0253, New England BioLabs) and $2 \mu \mathrm{l}$ Oligo (dT) primers (PC2450, Solarbio). Subsequently, PCR mixes contained $1 \mu \mathrm{l}$ cDNA, $1 \mu \mathrm{l}$ specific primers, and $10 \mu \mathrm{l} 2 \mathrm{X}$ PCR SuperMix (AS111, TransGen Biotech) in a final volume of $20 \mu \mathrm{l}$. The primers used were: Krt86 forward, 5'-CAGCAGGTTCGCGGCCTTCA-3'; reverse, 5'-GCCTCTGCGTTGGCCTCCAG-3; Atcb forward, 5' -TGGAATCCTGTGGCATCCATGAAAC-3'; and Atcb reverse, 5'-TAAAACGCAGCTCAGTAA CAGTCCG-3. The reaction conditions were as follows: polymerase activation and DNA denaturation (one cycle at $95^{\circ} \mathrm{C}$ for $30 \mathrm{~s}$ ); denaturation, annealing, and extension (30 cycles of $95^{\circ} \mathrm{C}$ for $30 \mathrm{~s}, 60^{\circ} \mathrm{C}$ for $30 \mathrm{~s}$ and $72^{\circ} \mathrm{C}$ for 30 s); and extension $\left(72^{\circ} \mathrm{C}, 10 \mathrm{~min}\right)$.

Real-time PCR was performed with the Agilent StrataGene Mx3005P QPCR detection system (Agilent StrataGene, USA). cDNA $(1 \mu \mathrm{l})$ and $0.5 \mu \mathrm{M}$ primers were adjusted with RNase-free water to a volume of $10 \mu \mathrm{l}$, followed by the addition of $10 \mu \mathrm{L}$ SYBR Green master mix (A6002, Promega). Primers for the detection of Krt86 were forward, 5'-GAGCAACATGGAGCCTCTGT-3' and reverse, 5'-CCCGGAGTGCAACTTCTTCT-3, while for Atcb they were forward, 5'-TGGAATCCTGTGGCATCC ATGAAAC-3' and reverse, 5'-TAAAACGCAGCTCA GTAACAGTCCG-3'. Reactions took place at $95^{\circ} \mathrm{C}$ for 1 min, followed by 40 cycles of $95^{\circ} \mathrm{C}$ for $15 \mathrm{~s}$ and $60^{\circ} \mathrm{C}$ for 1 min. The program for the melting curve analysis was $95^{\circ} \mathrm{C}$ for $5 \mathrm{~s}$ and $65^{\circ} \mathrm{C}$ for $1 \mathrm{~min}$. The mRNA expression levels were quantified using the $2^{-\Delta \Delta \mathrm{Ct}}$ method. Amplification of $A t c b$ mRNA was performed to normalise the data. Mouse skin was used as a positive control (pos), while water was used as a negative control (neg).

\section{Immunostaining}

Mouse uteri were cut into small pieces, fixed in Bouin's solution for $24 \mathrm{~h}$, dehydrated, and embedded in paraffin. Five $\mu \mathrm{m}$ paraffin-embedded endometrial sections were deparaffinised and rehydrated. Endogenous peroxidase activity was blocked by incubating the sections in $3 \%$ peroxide in methanol for $10 \mathrm{~min}$ at room temperature. After three washes in phosphate-buffered saline (PBS), nonspecific binding was blocked in PBS with 5\% rabbit serum for $1 \mathrm{~h}$ at room temperature, followed by incubation overnight at $4{ }^{\circ} \mathrm{C}$ with $1: 100$ goat anti-KRT86 primary antibody (sc-168332, Santa Cruz Biotechnology) in blocking solution. After a further three washes in PBS, the sections were incubated for $1 \mathrm{~h}$ at $37^{\circ} \mathrm{C}$ with $1: 100$ horseradish peroxidase (HRP)-conjugated rabbit antigoat IgG (ZB-2306, Zhongshan Biotechnology) in blocking solution, as the secondary antibody. Antibody labelling was detected with fresh diaminobenzidine (DAB) solution (ZLI-9017, Zhongshan Biotechnology), and sections were counterstained with Harris hematoxylin. Photographs of the slides were taken using a Leica microscope.

\section{Western blot}

Proteins were extracted from uterine tissues at various stages after treatment, utilising ice-cold radioimmunoprecipitation assay (RIPA) buffer that was supplemented with protease inhibitor phenylmethylsulfonyl fluoride (PMSF; Beyotime). Protein concentrations were determined using a BCA Protein Assay Kit (Beyotime). Twenty $\mu$ g protein samples were separated by $12 \%$ sodium dodecyl sulphate-polyacrylamide gel electrophoresis and then transferred to polyvinylidene difluoride (PVDF) membranes. The PVDF membranes were blocked with $5 \%$ non-fat milk in TRIS-buffered saline at room temperature for $1 \mathrm{~h}$, and then incubated in primary antibodies against KRT86 (Santa Cruz) and betaactin (1:1000; Beyotime) at $4{ }^{\circ} \mathrm{C}$ overnight. After washing three times, the PVDF membranes were probed with secondary antibodies, 1:10,000 HRP-conjugated rabbit anti-goat or goat anti-mouse IgG (Zhongshan Biotechnology), for $1 \mathrm{~h}$ at room temperature. Finally, HRPtagged bands were visualised using the Immobilon western chemiluminescent HRP substrate (WBKLS500, Milipore), and chemiluminescence intensity of each band was quantified by Image software. 


\section{Statistical analysis}

Statistical analysis was carried out using the GraphPad 6 program. Each experiment was performed at least three times. One-way analysis of variance, followed by a least-significant-difference test, was used for statistical comparisons among multiple groups. Statistically significant differences were determined at $P<0.05$.

\section{Abbreviations}

AA: Alopecia areata; E2: Oestradiol; IVF: in vitro fertilisation; KRT86: Keratin 86; P4: Progesterone; VEGF: Vascular endothelial growth factor

\section{Acknowledgements}

Not applicable.

\section{Authors' contributions}

$\mathrm{HZ}$ designed the experiments and analyzed the experimental results. $\mathrm{HZ}$ and HSZ carried out the experiments and wrote the manuscript. XW, XC and $L J$ helped to finish the experiments and the manuscript. All authors read and approved the final manuscript.

\section{Funding}

This work was supported by the National Natural Science Foundation of China (No. 31600943) and the Department of Education of Liaoning Province (No. L2015157). The funding bodies had no role in the design of the study and collection, analysis, and interpretation of data and in writing the manuscript.

\section{Availability of data and materials}

All data generated or analysed during this study are included in this published article.

\section{Ethics approval and consent to participate}

The Guidelines for the Care and Use of Animals in Research were followed. Care of mice and their handling were conducted in accordance with the Animal Research Committee guidelines of Dalian Medical University, China. The institute does not issue a number to each animal study, but there is an ethical committee to guide animal use. The contents in present study regarding animal uses were approved by the Animal Research Committee guidelines of Dalian Medical University.

\section{Consent for publication}

Not applicable.

\section{Competing interests}

The authors declare that they have no competing interests.

\section{Author details}

${ }^{1}$ College of Basic Medical Sciences, Dalian Medical University, No. 9 West Section Lvshun South Road, Dalian 116044, Liaoning, China. ${ }^{2}$ Center for Reproduction and Health Development, Shenzhen Institutes of Advanced Technology, Chinese Academy of Sciences, Shenzhen 518055, China.

\section{Received: 12 September 2019 Accepted: 27 January 2020}

Published online: 07 February 2020

\section{References}

1. Cha J, Sun X, Dey SK. Mechanisms of implantation: strategies for successful pregnancy. Nat Med. 2012;18(12):1754-67.

2. Gu LH, Coulombe PA. Keratin function in skin epithelia: a broadening palette with surprising shades. Curr Opin Cell Biol. 2007;19(1):13-23.

3. Magin TM, Vijayaraj P, Leube RE. Structural and regulatory functions of keratins. Exp Cell Res. 2007:313(10):2021-32.

4. Bragulla HH, Homberger DG. Structure and functions of keratin proteins in simple, stratified, keratinized and cornified epithelia. J Anat. 2009;214(4):516-59.

5. Winter $H$, Rogers MA, Langbein L, Stevens HP, Leigh IM, Labreze C, Roul S, Taieb A, Krieg T, Schweizer J. Mutations in the hair cortex keratin hHb6 cause the inherited hair disease monilethrix. Nat Genet. 1997;16(4):372-4.
6. Redler S, Pasternack SM, Wolf S, Stienen D, Wenzel J, Nothen MM, Betz RC. A novel KRT86 mutation in a Turkish family with monilethrix, and identification of maternal mosaicism. Clin Exp Dermatol. 2015; 40(7):781-5.

7. Zhang Y, Chen Q, Zhang H, Wang Q, Li R, Jin Y, Wang H, Ma T, Qiao J, Duan E. Aquaporin-dependent excessive intrauterine fluid accumulation is a major contributor in hyper-estrogen induced aberrant embryo implantation. Cell Res. 2015:25(1):139-42.

8. Zhang S, Kong S, Wang B, Cheng X, Chen Y, Wu W, Wang Q, Shi J, Zhang Y, Wang $S$, et al. Uterine Rbpj is required for embryonic-uterine orientation and decidual remodeling via notch pathway-independent and -dependent mechanisms. Cell Res. 2014;24(8):925-42.

9. Goodrich LV, Strutt D. Principles of planar polarity in animal development Development. 2011;138(10):1877-92.

10. Zhang S, Lin H, Kong S, Wang S, Wang H, Wang H, Armant DR. Physiological and molecular determinants of embryo implantation. Mol Asp Med. 2013;34(5):939-80.

11. Li Q, Wang J, Armant DR, Bagchi MK, Bagchi IC. Calcitonin down-regulates E-cadherin expression in rodent uterine epithelium during implantation. J Biol Chem. 2002:277(48):46447-55.

12. Daikoku T, Cha J, Sun X, Tranguch S, Xie H, Fujita T, Hirota Y, Lydon J, DeMayo F, Maxson R, et al. Conditional deletion of Msx homeobox genes in the uterus inhibits blastocyst implantation by altering uterine receptivity. Dev Cell. 2011;21(6):1014-25.

13. Nallasamy S, Li Q, Bagchi MK, Bagchi IC. Msx homeobox genes critically regulate embryo implantation by controlling paracrine signaling between uterine stroma and epithelium. PLoS Genet. 2012;8(2): e1002500.

14. Ma L, Xu J, Coulombe PA, Wirtz D. Keratin filament suspensions show unique micromechanical properties. J Biol Chem. 1999;274(27):19145-51.

15. Janmey PA, Euteneuer U, Traub P, Schliwa M. Viscoelastic properties of vimentin compared with other filamentous biopolymer networks. J Cell Biol. 1991:113(1):155-60.

16. Ji Y, Lu X, Zhong Q, Liu P, An Y, Zhang Y, Zhang S, Jia R, Tesfamariam IG, Kahsay AG, et al. Transcriptional profiling of mouse uterus at preimplantation stage under VEGF repression. PLoS One. 2013;8(2):e57287.

17. Shimomura Y, Wajid M, Kurban M, Sato N, Christiano AM. Mutations in the keratin 85 (KRT85/hHb5) gene underlie pure hair and nail ectodermal dysplasia. J Invest Dermatol. 2010;130(3):892-5.

18. Suarez-Farinas M, Ungar B, Noda S, Shroff A, Mansouri Y, Fuentes-Duculan J, Czernik $A$, Zheng $X$, Estrada YD, Xu H, et al. Alopecia areata profiling shows $\mathrm{TH} 1, \mathrm{TH} 2$, and IL-23 cytokine activation without parallel TH17/TH22 skewing. J Allergy Clin Immunol. 2015;136(5):1277-87.

19. Shimomura $Y$, Ito M. Human hair keratin-associated proteins. J Investig Dermatol Symp Proc. 2005;10(3):230-3.

20. Schweizer J, Langbein L, Rogers MA, Winter $H$. Hair follicle-specific keratins and their diseases. Exp Cell Res. 2007;313(10):2010-20.

21. Nanashima N, Akita M, Yamada T, Shimizu T, Nakano H, Fan Y, Tsuchida S. The hairless phenotype of the Hirosaki hairless rat is due to the deletion of an 80-kb genomic DNA containing five basic keratin genes. J Biol Chem. 2008;283(24):16868-75

22. Osz J, Brelivet Y, Peluso-Ittis C, Cura V, Eiler S, Ruff M, Bourguet W, Rochel N, Moras D. Structural basis for a molecular allosteric control mechanism of cofactor binding to nuclear receptors. Proc Natl Acad Sci U S A. 2012;109(10):E588-94.

23. Choi KC, Jeung EB. The biomarker and endocrine disruptors in mammals. J Reprod Dev. 2003;49(5):337-45.

24. Lee HR, Kim TH, Choi KC. Functions and physiological roles of two types of estrogen receptors, ERalpha and ERbeta, identified by estrogen receptor knockout mouse. Lab Anim Res. 2012;28(2):71-6.

25. Chen M, Wolfe A, Wang X, Chang C, Yeh S, Radovick S. Generation and characterization of a complete null estrogen receptor alpha mouse using Cre/LoxP technology. Mol Cell Biochem. 2009;321(1-2): $145-53$.

26. Jayachandran M, Preston CC, Hunter LW, Jahangir A, Owen WG, Korach KS, Miller VM. Loss of estrogen receptor beta decreases mitochondrial energetic potential and increases thrombogenicity of platelets in aged female mice. Age (Dordr). 2010;32(1):109-21

27. Chen M, Hsu I, Wolfe A, Radovick S, Huang K, Yu S, Chang C, Messing EM, Yeh S. Defects of prostate development and reproductive system in the estrogen receptor-alpha null male mice. Endocrinology. 2009; 150(1):251-9. 
28. Hewitt SC, Kissling GE, Fieselamsn KE, Jayes FL, Gerrish KE and Korach KS. Analysis of the acute and chronic estrogen receptor-a (ERa/Esr1)-regulated transcriptomes in 17ß-estradiol (17BE2)-treated mouse uterus, v1.0.NURSA Datasets. 2010. https://doi.org/10.1621/vKbmb7vVqB

29. Hewitt SC, Kissling GE, Fieselman KE, Jayes FL, Gerrish KE, Korach KS. Biological and biochemical consequences of global deletion of exon 3 from the ER alpha gene. FASEB journal : official publication of the Federation of American Societies for Experimental Biology. 2010;24(12):4660-7.

30. Zhao C, Putnik M, Gustafsson JA and Dahlman-Wright K. Analysis of the estrogen receptor- $\beta$ (ERß/ESR2)-regulated transcriptome in HEK293 cells, v1. 0.NURSA Datasets. 2009. https://doi.org/10.1621/cinGeUpl3V.

31. Zhao C, Putnik M, Gustafsson JA, Dahlman-Wright K. Microarray analysis of altered gene expression in ERbeta-overexpressing HEK293 cells. Endocrine. 2009;36(2):224-32.

32. Chang EC and Katzenellenbogen BS. Analysis of the 17ß-estradiol (17BE2)regulated, estrogen receptor- $\beta$ (ER $/ E$ ESR2)-dependent transcriptome in MCF-7 breast cancer cells, v1.0.NURSA Datasets. 2006. https://doi.org/10. 1621/fbqRi3ck3S

33. Chang EC, Frasor J, Komm B, Katzenellenbogen BS. Impact of estrogen receptor beta on gene networks regulated by estrogen receptor alpha in breast cancer cells. Endocrinology. 2006;147(10):4831-42.

34. Choleris E, Clipperton AE, Phan A, Kavaliers M. Estrogen receptor beta agonists in neurobehavioral investigations. Curr Opin Investig Drugs. 2008; 9(7):760-73.

35. Lim HJ, Wang H. Uterine disorders and pregnancy complications: insights from mouse models. J Clin Invest. 2010;120(4):1004-15.

\section{Publisher's Note}

Springer Nature remains neutral with regard to jurisdictional claims in published maps and institutional affiliations.

Ready to submit your research? Choose BMC and benefit from:

- fast, convenient online submission

- thorough peer review by experienced researchers in your field

- rapid publication on acceptance

- support for research data, including large and complex data types

- gold Open Access which fosters wider collaboration and increased citations

- maximum visibility for your research: over $100 \mathrm{M}$ website views per year

At $\mathrm{BMC}$, research is always in progress.

Learn more biomedcentral.com/submissions 